\section{AQUISIÇÃO DE CAPITAL CULTURAL NO \\ PROCESSO DE LUTA PELA TERRA NO SUL DA BAHIA: DA MILITÂNCIA DOS PAIS AO ACESSO À UNIVERSIDADE}

Jheyds Lemos Farias 1 Elis Cristina Fiamengue2 Dulce Consuelo Andreatta Whitaker3

Resumo: Este artigo é resultado de um trabalho apresentado ao final da disciplina Educação e Sociedade, ministrada pela professora Elis Fiamengue no curso de História na Universidade Estadual de Santa Cruz(UESC), em Ilhéus/Bahia. No decorrer da disciplina foram discutidos diferentes autores, entre os quais Paulo Freire e Pierre Bourdieu e, ao final, os alunos foram instigados a fazer um exercício de memória, recordando sua trajetória, refletindo sobre a mesma e relacionando-a aos processos de aquisição de capital cultural. A partir da construção de um memorial sobre a trajetória de luta pela terra dos pais, o aluno Jheyds Lemos Farias elaborou uma reflexão acerca das formas de aquisição do capital cultural nos processos políticos de demanda por terra para reforma agrária no sul e extremo sul da Bahia.

Palavras-chave: Memória; Capital Cultural; Luta Pela Terra
Abstract:This paper is the result of a work presented inside "Education and Society" course, taught by Professor Elis Fiamengue, as part of the History graduation course offered at Santa Cruz State University ("Universidade Estadual de Santa Cruz" - UESC), located at the city of Ilhéus, Bahia State. In the program of this course, several authors were discussed, such as Paulo Freire and Pierre Bourdieu, and in the end of the course the students were motivated to do a memory exercise, remembering their lives, thinking about it and relating it to capital cultural acquisition processes. Starting with the construction of a text remembering the course of the struggle for land made by his parents, the stutend Jhedys Lemos Farias made a thinking about the ways of cultural capital acquisition on the political processes of land demand, seeking land reform at the south and south ends of Bahia state.

Keywords: Memory; Fight For Land; Cultural Capital

\section{Introdução}

As Ciências Sociais, na contemporaneidade, têm tomado cuidados para satisfazer as exigências de um momento histórico no qual, cada vez mais, os sujeitos oprimidos querem fazer valer sua própria voz. Como bem lembra Thompson (1998) no seu livro A Voz do Passado, não se trata só de dar voz aos sujeitos, já que de certa forma a voz já lhes foi dada. Trata-se, agora, de dar ouvidos aos participantes de pesquisas em áreas humanas, para que eles recordem, interpretem e expliquem suas trajetórias. É o que faremos com um aluno da graduação em História da Universidade Estadual de Santa Cruz (UESC), Jheyds Lemos Farias, cujo depoimento rico de interpretações, demonstra como uma atividade de luta pode dinamizar a aprendizagem pelos estímulos políticos que atuam sobre motivações.

Acreditamos que nosso aluno construiu um documento precioso para estudos de aprendizagem em futuro próximo ou distante, quando poderá ser feito pelo próprio autor do documento ou por pesquisadores interessados na complexidade da experiência pedagógica propiciada pela luta.

Importante lembrar que documentos aparentemente sem importância têm sido aproveitados pela História do cotidiano e mesmo pela "grande História" e, inclusive, tem despertado o interesse dos sociólogos, conforme destacam Whitaker, Fiamengue e Velôso (2010).

Ou seja, publicamos este depoimento como contribuição às diferentes áreas de pesquisa, já que além de dar voz e ouvido aos oprimidos do 
sistema, temos o compromisso com a ciência e esta exige novas abordagens, interpretações e iluminações teóricas que possam tornar cada vez mais compreensíveis à vida social de modo geral e ao contexto do aprendizado na luta pela terra mais especificamente.

Apresentamos, então, um texto em primeira pessoa, no qual o autor elabora reflexões e discute as elaborações de Pierre Bourdieu acerca do acesso ao capital cultural.

\section{Metodologia}

No segundo semestre de 2015 ministrei a disciplina Educação e Sociedade no curso de História na UESC e como trabalho de avaliação final solicitei aos alunos que construíssem um memorial na expectativa de que pudessem contar suas histórias e elaborassem reflexões acerca dos inúmeros processos excludentes presentes no sistema escolar, mas que também pudessem identificar as resistências.

Desse modo, os alunos foram convidados a escrever relatos bastante minuciosos e a rememorar suas trajetórias de vida, identificando os momentos e as oportunidades nas quais puderam ter acesso ao capital cultural disponível.

Essa proposta de trabalho final de avaliação na disciplina Educação e Sociedade ancorava-se na perspectiva de uma auto-etnografia que permitisse aos alunos refletirem sobre a trajetória que percorreram a caminho da Universidade.

O aluno Jheyds Lemos Farias elaborou sua reflexão a partir da trajetória de luta pela terra de seus pais. Seu memorial demonstra a efetividade da pedagogia da luta, tal como Paulo Freire nos mostra (FREIRE, 2005), bem como apresenta os processos e possibilidades de aquisição de capital cultural, o que permitiu o acesso ao ensino superior.

No ano de 2016 apresentamos este trabalho no VII Simpósio sobre Reforma Agrária e Questões Rurais e reescrevemos o texto com a contribuição da professora Dulce Whitaker na perspectiva de deixar que os agentes sociais falem por si e que reflitam cientificamente acerca dos processos que insistem em excluí-los, mostrando como elaboram estratégias de resistência à essa exclusão.

\section{O Memorial}

Minha família sempre teve tradição rural, apesar disso, quando nasci em setembro 1992, meus pais moravam num conjunto habitacional do BANCO NACIONAL DE HABITAÇÃO (BNH), chamado Urbis III, em Eunápolis. Os embriões (nome que era dado às habitações do conjunto) eram compostos somente por uma sala/cozinha e um quarto, ao lado de um pequeno terreno, onde os mais afortunados logo construíram, transformando tudo em moradia. Minha família não estava nessa categoria, e moramos ainda muitos anos no embrião antes de conseguir construir a tão sonhada casa (que não era ainda própria, pois permanecia a dívida no banco), e que anos depois foi construída num mutirão dos companheiros do movimento, e muito tempo depois (já nos anos 2000) finalmente quitada.

Com dois filhos (eu e Jaks, meu irmão um ano mais velho), a instabilidade econômica dos anos 90, e uma dívida no banco, meus pais trabalhavam arduamente para que nada nos faltasse. Minha mãe, Rozelene Lemos (ou só Roze, como ela prefere) estudou até concluir o ensino fundamental (fazendo curso técnico integrado ao ensino médio, posteriormente) é de Minas Gerais, e sua família veio para a Bahia quando ela ainda era adolescente, batalhando pela estabilidade em um estado de costumes diferentes, e numa região litorânea característica pelas invasões irregulares de terra e oportunismo. Quando nasci, ela trabalhava como caixa de uma empresa de supermercados regional (fruto de uma oligarquia política da região) num regime de trabalho cansativo e extremamente estressante, do qual cada centavo que faltasse em qualquer dos caixas era imediatamente reduzido do salário dos funcionários. Meu pai (Juenildo Oliveira, ou Zuza, como a vida o rebatizou com o tempo) estudou até a primeira série e depois de adulto cursou até a quarta série (posteriormente, estudando numa comissão certificadora, para conseguir documentação necessária para um curso técnico em agropecuária sustentável, integrado ao ensino médio, que concluiu recentemente), é o filho mais velho de uma família de mais de doze filhos, que sofreu com o êxodo rural quando o dono da fazenda, em que todos moravam de favor, vendeu a propriedade expulsando os funcionários. Graças ao sistema latifundiário, os proprietários dessas fazendas raramente as visitavam, pois não se interessavam por nada relacionado ao rural, exceto os lucros advindos do trabalho desempenhado por pouquíssimos funcionários, em muitos casos um ou mais grupos familiares. Da vida no campo desfrutam somente em raras ocasiões, em geral de festividades, onde os trabalhadores se desdobram ao máximo para minimizar as queixas acerca do imóvel, que aos olhos do patrão sempre existiam, apesar dos cuidados. Graças a essa ausência, meus 
avós, paralelamente ao trabalho da fazenda, adquiriram algumas reses de animais, que foram vendidos e serviram para comprar uma casa na periferia da cidade de Itabela, a $30 \mathrm{~km}$ de Eunápolis. Nessa época, todo trabalho era bem-vindo, e meu pai cuidava dos irmãos mais novos e também da lavagem da roupa, além de outros "bicos" que ajudavam nas despesas de casa. Ainda na adolescência iniciou-se como ajudante em oficinas mecânicas e quando nasci, era um dos pintores de automóveis conceituado na cidade.

Ambos eram católicos e faziam parte de um grupo de jovens da igreja, que desenvolvia algumas atividades filantrópicas, como arrecadação de alimentos, agasalhos, mutirões para limpeza de terrenos, construção e reforma de casas, entre outras. Nesse contexto, conheceram alguns outros militantes, que faziam parte do movimento sindical rural da região e os levaram a participar de reuniões com intuito de conhecer os ideais e práticas dos sindicalistas. Com muita coragem, em fins de 1993, resolveram se unir a um movimento novo, que acabava de chegar com representatividade e organização na região. O Movimento de Luta pela Terra (MLT) que surgiu no Sul da Bahia, com a crise da lavoura cacaueira, devido a propagação de uma praga denominada popularmente "Vassoura-de-bruxa", que se espalhou pelos cacauais da região reduzindo drasticamente a produção. Em decorrência disso, demissões em massa fizeram com que inúmeras pessoas migrassem para as periferias das cidades sul - baianas. O movimento sindical, aliado a alguns estudantes e outras forças não governamentais, resolveram se unir em defesa dessas pessoas, criando então um movimento unificado que visava, através de ocupações de terras improdutivas e/ou devolutas, forçar o estado brasileiro a realizar uma reforma agrária popular. O movimento rapidamente ganhou força, aumentando sua área de atuação para diversas regiões da Bahia, inclusive a região Extremo Sul, onde fica o município de Eunápolis.

Quando meu pai, com dois filhos menores de dois anos, resolveu abandonar a oficina mecânica onde trabalhava, causou espanto na maior parte dos colegas, pois pela convivência, todos sabiam dos ideais igualitários e de liberdade que meu pai cultivava, mas disseram que era loucura abandonar a segurança de profissional qualificado que ele tinha. Ele, por sua vez, alegou aos colegas que não havia segurança alguma em ser subordinado a um sistema semi-escravista, e que iria voltar ao campo para lutar por liberdade. Assim, no fim de 1993, o MLT se organizou para ocupar uma fazenda onde havia as instalações de uma usina para processamento de cana-de-açúcar e milhares de hectares de improdutividade, pois há anos tudo estava abandonado. Assim, iniciou-se a "longa marcha do campesinato" rumo à ocupação da fazenda Embaúba, com centenas de famílias de trabalhadores rurais expulsos que viam o sonho de retornar ao campo, e também famílias de trabalhadores de setores mais urbanos que viam na reforma agrária alternativa para melhoria da região. Dentre estas, minha família.

Devido à experiência dialética que meus pais tinham graças, ao grupo de jovens, e, também às diversas reuniões da associação de moradores, sindicato, entre outras, logo assumiram posições de liderança no acampamento. Meu pai assumiu uma das coordenações e minha mãe a secretaria. Como ela já havia dado aula pelo município, como professora leiga, assumiu posteriormente as aulas. Com pouco tempo de acampamento, o movimento se preocupou com a construção de uma escola, onde aconteceriam as principais reuniões e a alfabetização dos companheiros. No entanto, no dia da ocupação da fazenda, os companheiros perceberam uma árvore que proporcionava uma grande sombra, e, pela falta de construção adequada, fizeram ali mesmo a primeira assembleia. Isso se tornou tradição nessa comunidade, à exceção dos dias de chuva, todas as assembleias eram feitas sob a sombra da árvore, de maneira que a escola ganhou cada vez mais ares de ambiente de ensino, com inúmeras colagens nas rudimentares paredes de madeira, quadro de giz, e muita atividade. Além das aulas, os coordenadores do acampamento sempre promoviam palestras temáticas e formações políticas, como minicursos, oficinas, entre outras ações.

Nessa época, eu ainda era muito novo para participar de todas as atividades, mas ia regularmente à escola que possuía três turmas, uma inicial no turno matutino, da qual eu participava com outras crianças e tinha como objetivo alfabetização de crianças e adultos, uma à tarde, que servia para adolescentes que já estavam em idade escolar, mas que devido ao contexto socioeconômico da época não tinham condições de estudar nas escolas do município, para não ficarem completamente desassistidas estudavam e participavam das diversas atividades. E, ainda, uma turma noturna, que à luz do candeeiro e do "zé-gás" (nome popular conferido aos lampiões a gás), chegavam das lavouras cansados do trabalho diário e ainda encontravam disposição para ir estudar.

Vale ressaltar que o contexto histórico dos anos 1990, para movimentos de luta por reforma agrária na Bahia, não era nada tranquilo. Os governos 
locais e estaduais representavam oligarquias que eram detentoras das terras pleiteadas, o que atrasava o processo legal de aquisição de terras por parte dos órgãos competentes do Estado, assim, reinava um clima de insegurança jurídica, pois inúmeros mandatos de reintegração de posse eram executados arbitrariamente e com uso excessivo de força e as manifestações fora do acampamento, no Instituto Nacional de Colonização e Reforma Agrária ( INCRA), e outros órgãos responsáveis, eram recepcionados com a tropa de choque. Em suma, o governo do Estado da Bahia não tinha um diálogo aberto com os movimentos, todos os processos eram tensos, principalmente nos acampamentos, onde a "jagunçada" tinha a função de executar ordens dos fazendeiros grileiros e latifundiários. Políticas públicas básicas de subsistência como transporte escolar, visita médica, cestas básicas para os acampados, lonas pretas para construção de barracos, nada disso era assegurado pelo Estado que se regia por uma cartilha excludente e omissa, abrindo espaço para inúmeras violações de direito.

Apesar das divisões em turmas, de acordo com a dinâmica das atividades coletivas do acampamento, todos poderiam ir livremente à escola em qualquer dos turnos, muitas vezes iam tirar dúvidas gerais sobre inscrições em embalagens de remédio, rótulo de produtos, entre outras, e gradualmente notavam a necessidade de estudar para vencer as adversidades do dia-a-dia, de modo que mais da metade das famílias (cerca de 200 famílias) tinha pelo menos um membro participando ativamente da escola. Outro atrativo na escola era a diferença. Os acampados que já haviam estudado em instituições formais de ensino, sentiam-se estupefatos com a maneira como se dava a aula, os que nunca haviam estudado comentavam que se soubessem que a escola funcionava assim ingressariam antes. Desde a arrumação da sala em círculo, do diálogo com linguagem simples, as atividades elaboradas com palavras e símbolos locais e regionais e outras metodologias simples e diversificadas faziam com que todo o cansaço físico fosse esquecido. A escola era tida como um momento de lazer, permitindo que o aprendizado fosse agradável e fortificando os laços de amizade e militância dentro da comunidade, pois era também um espaço de compartilhamento de experiências e saberes.

Como minha mãe era professora dessa inovadora escola, eu estava sempre que podia com ela, acompanhando de perto as atividades das outras turmas, e participando da turma matutina de alfabetização, juntamente com meu irmão e as demais crianças. Apesar de novos, as abordagens temáticas já existiam na classe. Havia temas corriqueiros para discussão, como comportamento, respeito aos mais velhos, a história do movimento, o contexto histórico, político e até jurídico da área pleiteada para assentamento, entre outros. Para os acampados estudantes, mesmo alguns adolescentes que já frequentaram escolas formais, tudo era muito novo e cativante, diferente das escolas da cidade, onde os membros da zona rural são constantemente excluídos ou maltratados por sua condição de cidadãos do campo.

Porém, enquanto os acampados se organizavam para resistir através da educação diferenciada, os proprietários agiam no sentido de desestruturar a comunidade, com pistoleiros e a conivência de agentes do Estado, como policiais e oficiais de justiça. Houve nesse acampamento, cerca de treze despejos por mandato de reintegração de posse, quando se mudava todo o quadro da vida dos acampados, que "despejados", voltavam para as beiras de estradas e rodovias. Uma situação deveras complexa, pois se dentro das áreas pleiteadas para assentamento a vida era difícil, na beira das estradas era muito pior e mais perigosa, com o trânsito de veículos pesados, o risco de atropelamentos era iminente. Também aumentavam os casos de problemas de saúde relacionados à respiração, devido à poeira, e o pior, sem condições mínimas de subsistência, muitos companheiros que almejavam a independência dos modelos financeiros da cidade, acabavam tendo que voltar do campo para a cidade em busca de trabalhos assalariados, onde recebiam diárias para desenvolver trabalhos extenuantes e nunca bem remuneradas.

Não havia nessas condições estruturação básica para a escola continuar funcionando, então nos períodos de despejo, a maior parte dos acampados ficava sem estudar, alguns outros tentavam matricular seus filhos nas escolas do município, o que fazia com que estes andassem cerca de oito quilômetros até o ponto de ônibus mais próximo para ir e a mesma distância para voltar ao acampamento, nas margens da estrada. E, alguns poucos, incentivados pelas lideranças da comunidade, mesmo na beira da estrada, continuavam seus processos de aprendizagem e discussão.

O processo de despejo, aos militantes do MLT, era uma via de mão dupla, por que ao mesmo tempo em que todo um trabalho construído devia ser desfeito ou deixado para traz (a estrutura básica do acampamento, as barracas de lona eram desmontadas e levadas para criar as novas "casas" na beira da estrada e muitas vezes as lavouras eram completamente destruídas pelos proprietários assim que se fazia cumprir a reintegração de posse). Por outro lado, as constantes negociações com o governo do Estado, as idas a Salvador para tentar adiantar o processo de aquisição das áreas para reforma agrária, 
a organização da base, para que não houvesse dispersão dos acampados, tudo isso desempenhava uma função muito clara de inserir conhecimentos diversos, que em situação de tranquilidade nunca seriam inseridos. A tensão desse tipo de vida por si só, faz com que os companheiros sintetizem métodos de subsistência coletiva, aprendendo com os erros e acertos e aplicando os novos aprendizados nas próximas ocupações. Um exemplo dessa situação: coordenadores do movimento contataram o proprietário da fazenda vizinha à área pleiteada pelo MLT para assentamento, assim, a partir de algumas reintegrações de posse passamos simplesmente a transpor a cerca para a área ao lado, ao invés de andar mais de seis quilômetros "com a casa na cabeça" (expressão utilizada pelos acampados). A primeira vez que utilizamos essa estratégia, os policiais que vieram executar a reintegração de posse ficaram desconfiados, achando que assim que tivessem terminado seus trabalhos, iríamos voltar para a área, o que realmente acontecia, mas quando julgávamos apropriado (a invisível escola dos militantes, ensinou aos companheiros um subterfúgio legal, que permitia que voltássemos à área do despejo em geral 24 horas após o despejo). Além disso, o Estado tem seu preconceito linguístico, suas formas hierárquicas e até oligárquicas, onde os militantes, em constantes reuniões, absorvem os trejeitos, a maneira de falar dos representantes do Estado. Em suma, todo o processo de acampamento que (não necessariamente) culmina em assentamento, é parte fundamental de um processo de aprendizagem do qual os acampados, em geral pessoas de tradição rural, assimilam e traduzem as linguagens e costumes de um Estado que se mostra sempre urbano, desligado das questões agrárias. Nesse sentido, os homens e mulheres da luta, visando não serem lesados em seus direitos fundamentais, se adaptaram a dialogar com juízes, promotores, advogados e outras figuras públicas, apesar de que a maioria destes possui pouca ou nenhuma escolaridade.

Essas constantes intervenções externas da coordenação, denotavam a organização do acampamento e, direta ou indiretamente, faziam com que as lideranças da comunidade aparecessem no cenário político local, o que por sua vez era muito positivo para a luta, aumentava o prestigio político de o movimento atuar frente aos setores de interesse participando ativamente das decisões políticas municipais e regionais; mas, por outro lado, tinha o trágico fator de trazer ao conhecimento dos fazendeiros e latifundiários quem eram as pessoas que desempenhavam funções coordenativas, possibilitando a estes iniciar o processo de desestabilização das lideranças através de ameaças e pistolagem, para assim facilitar a desestruturação de toda a comunidade. Como coordenadores de um movimento social que luta por reforma agrária, num país com histórico de "latifundismo agricola-feudal" (CASTRO, 1984) meus pais foram vítimas de ameaças em inúmeros contextos de acampamentos durante toda a vida, e no acampamento Embaúba, especificamente; as ameaças eram agravadas por rondas que os pistoleiros faziam em volta do acampamento, ameaçando trabalhadores que voltavam de suas lavouras e mandando recados ameaçadores às lideranças locais. Em situações como essas, o MLT procura reduzir a participação de determinadas lideranças em áreas de contexto conflituoso, fazendo com que as mesmas atuem em ocupações de outras regiões, que ainda se encontrem em estado menos avançado no processo de acampamento, ainda em fase de organização, ou simplesmente reduzam a presença nas áreas de conflito, participando somente em situações especificas, como assembleias organizativas. Algumas vezes durante a vida, tivemos que nos afastar do acampamento e voltar temporariamente para a cidade, outras, em situações mais tensas, ficávamos algum tempo fora da cidade. E foi assim, que por volta de 1997 tivemos que (aparentemente) sair do acampamento e voltar para a Urbis 3, estudando na escola do bairro. $\mathrm{Na}$ área, informações sigilosas estavam sendo veiculadas para os fazendeiros, o que fez com que as lideranças concluíssem haver algum dos acampados, muito provavelmente motivado pelo dinheiro do latifúndio, levando essas informações. Decidiuse então que seria mais seguro para nossa família atuar de fora para dentro. da comunidade.

Minha realidade acadêmica começou a mudar a partir daí, foi quando me vi inserido no modelo formal de ensino, onde todas as regras e normas já estavam pré-estabelecidas e não havia compartilhamento de experiências, somente a sala quadrada, com estudantes enfileirados e fadados a esconder suas habilidades que não fossem referentes ao interesse do professor. Tudo parecia muito diferente, e a adaptação não foi nada fácil. A escola formal da cidade, não debatia os temas corriqueiros que debatíamos no acampamento, tais como desigualdade, fome, capitalismo entre outros. Pelo contrário, percebemos que a educação que nos seria ministrada diferia em alguns aspectos do que estudávamos no acampamento, desde o formato da sala ao conteúdo aplicado, que com palavras e expressões alheias a nossa realidade cultural dificultava em muitos aspectos nossa compreensão sobre aquele novo ambiente escolar. No entanto, alfabetizados na escola diferenciada do 
acampamento - baseada na metodologia de Paulo Freire, contextualizava a educação à realidade popular local, abordando os temas pelas mais variadas perspectivas interpretativas, fazendo com que pessoas de todas as idades pudessem livremente participar das aulas e discussões contribuindo com os mais diversos conhecimentos, tornando o aprendizado mais democrático e abrangente - quando chegamos à escola da cidade (matriculados na turma de alfabetização, pois era necessário certificado de alfabetização para estudar nas séries subsequentes) notamos a diferença de nosso modo de pensar, dos demais estudantes. Além de já conseguir ler e escrever, eu e meu irmão conseguíamos fazer análises básicas que ainda não passavam pela cabeça das crianças daquelas turmas. Éramos vistos de maneira diferente pelos professores do bairro, que conheciam a trajetória de luta de meus pais e atribuíam também a isso o nosso êxito. Entraram em consenso de que poderíamos ser adiantados para a série seguinte (primeira série), pois nossos conhecimentos eram compatíveis com os conhecimentos desta turma (alguns professores sugeriram que meu irmão, por ser mais velho, fosse adiantado para a segunda série, mas meus pais optaram por continuarmos estudando juntos). Houve casos de levarmos notificações (bilhetinhos) para nossos pais, por provocarmos discussões em sala de aula ao questionar fatos de livros didáticos. Certa feita fomos retirados da sala e mandados mais cedo para casa com uma dessas notificações, por dizer que Pedro Álvares Cabral não tinha descoberto o Brasil, tinha na verdade invadido o território de inúmeras nações indígenas, contrapondo o que estava escrito no livro didático. Apesar de reconhecer que possuíamos conhecimentos diferenciados, os professores não alteravam em nada seus métodos e práticas, perpetuando o modelo que considerávamos (com nossas mentes de criança, em conversas com nossos pais) incompleto, pensávamos que a escola do acampamento era mais completa, e acreditávamos que as escolas públicas estaduais teriam mais contextualização com as realidades locais. Assim, quando concluímos a primeira série na escola do bairro, nos matriculamos no Colégio Estadual Professor Fernando Alban, onde ingressamos na segunda série e passamos por uma reformulação do que considerávamos ser o processo de aprendizado. Fomos, gradativamente, nos adaptando à escola da cidade. Inúmeros motivos nos levaram a ficar afastados do campo durante muitos anos, o fato de nossos pais, como inúmeros moradores da zona rural, possuírem um hipervalorização da educação na forma da escola (que na maioria das vezes representava a escola urbana, pois nessa época, as perspectivas da educação rural eram muito mais limitadas do que atualmente) fazerem um esforço considerável para nos manter na escola da cidade e ao mesmo tempo não perder a percepção da vida rural, do ambiente do acampamento, tanto que estudávamos na cidade e passávamos os fins de semana no acampamento. Além disso, o movimento se estruturou na cidade e também na região, o que aumentava a visibilidade de meus pais, enquanto lideranças, e, consequentemente, a preocupação dos mesmos com segurança.

Assim, estudamos todo o ensino fundamental no Colégio Estadual Prof. Fernando Alban, e quando chegamos à oitava série, decidimos juntamente com nossos pais que iríamos realizar o processo seletivo do Centro Federal de Educação Tecnológica da Bahia, posterior IFBA (CEFET) no qual fui aprovado e meu irmão reprovado, continuando o ensino médio no mesmo colégio. Ao ingressar no CEFET, notei mais fortemente a ideia da separação, das pessoas, das funções, dos conhecimentos. O sistema de ensino desses centros subdividia os alunos (no ato da inscrição para o processo seletivo) em duas modalidades: Ensino médio comum, ou ensino médio integrado a um curso técnico, informática ou edificação. Fui selecionado entre os dez primeiros para uma das turmas de informática. O CEFET ainda não havia aderido à política de cotas, de modo que a instituição ainda era completamente elitizada, agrupando os estudantes das principais escolas particulares da cidade e região e alguns (pouquíssimos) de escolas públicas, como era meu caso. Tive muita dificuldade de assimilação daquele ambiente, demasiadamente diverso do que eu era acostumado. Apesar de conseguir obter êxito em grande parte das disciplinas, houve muitas dificuldades de relacionamento com significativa parte dos alunos e também dos professores, que carregavam nos seus próprios discurssos em sala de aula, preconceitos que me atingiam, quando pautavam negros, "sem-terras", entre outros, o que me desmotivava de continuar. Diante de todos esses contratempos, fui "jubilado", termo que eles utilizavam para designar os estudantes que não conseguissem alcançar a meta e eram reprovados dois anos consecutivos na mesma série, tendo que abandonar a instituição ou refazer o processo seletivo. Nesse ínterim, meu irmão se formava no ensino médio pelo colégio estadual e ingressava em Educação Física, na UESC. No CEFET, apesar de ter sido expulso, tive muitos professores que me incentivaram a continuar estudando, e me mostraram que aquela era uma das portas que eu poderia abrir para entrar na universidade (que já era um objetivo meu há muito 
tempo), mas não a única.

Assim, quando saí do CEFET, ingressei novamente no Colégio Est. Prof. Fernando Alban, concluindo, enfim, meu primeiro ano do ensino médio. No ano seguinte, motivado por interesses musicais e esportivos, fui estudar no Colégio Estadual Doutor Cleriston Andrade, onde cursei os dois anos que faltavam para conclusão do ensino médio. Grande parte de estudantes e professores conhecidos do CEFET, se surpreenderam quando anunciei os resultados de quatro aprovações para ensino superior: Letras e História na Universidade do Estado da Bahia (UNEB), Geografia na Universidade Estadual do Sudoeste da Bahia (UESB) e História (UESC ), todas públicas. Estes tinham o pensamento limitado de que somente com a máxima formatação fornecida como educação pelo CEFET era possível alcançar o que eles consideravam o êxito, entrar na universidade. Optei por cursar história na UESC, por me identificar, desde o ensino fundamental, com os temas, e também por meu irmão já estar estabelecido no Salobrinho, Bairro onde está localizada a UESC, em Ilhéus, Bahia. Agora tento mais uma vez vencer as adversidades impostas por um modelo linear, que acredita na educação somente como objeto para alcançar objetivos, para então conseguir o tão sonhado certificado, que garantirá alegria a meus pais e, em tese, a redução dos preconceitos conferidos a mim pela condição de acampado rural em área de reforma agrária. Afinal, a escada para o "sucesso", segundo esse modelo, é o êxito máximo acadêmico proporcionado pelos "canudos" certificadores. Por minha parte, acredito nas possibilidades de escrever sobre minha realidade, e posso ressaltar que em cada setor de formatação social, denominados escolas, pelas quais passei, havia professores conscientes da verdadeira ação libertadora da educação, das reais e ilimitadas possibilidades de conhecimento, que são mutuamente compartilhados entre todos, professores que me fazem ter certeza de estar trilhando o melhor caminho, tanto pessoalmente, como para ajudar as comunidades tradicionais formadoras de opinião, com capacidade de revelar ao mundo, pensadores com outros preceitos.

\section{Considerações finais}

$\mathrm{O}$ texto deste memorial demonstra como diversos fatores culminaram para meu êxito acadêmico, dentre estes, fatores relacionados aos graus de instrução de meus pais e também fatores culturais absorvidos de ambos.
Com realidades similares, ambos viam no sistema escolar um fator de mobilidade social, investindo na educação de fora da comunidade em que vivíamos. Para Bourdieu ocorre exatamente o contrário, pois o sistema escolar legitima desigualdades, atuando como um dos mais eficazes fatores de conservação social. A herança cultural aparece nesse sistema, como dom natural do indivíduo, quando tudo tende a demonstrar que o que de fato ocorre é uma superestimação do dom social.

Para Bourdieu, há educação na escola, sob a forma de capital cultural, com objetivo de preparar os estudantes para setores específicos da sociedade. Assim, as instituições formulam o que julgam apropriado para o processo de educação arbitrariamente, segundo interesses e definições de uma classe social dominante naquele contexto histórico. A isso, Bourdieu denomina “Arbitrário Cultural Dominante". Pode-se perceber, a partir da leitura do memorial, que o histórico de militância social da família, possibilitou a realização de novas leituras de mundo, a partir das quais análises inerentes à condição de acampado rural almejando inserção no modelo educacional.

A tradição oral em casa, reuniões do movimento, o contexto históricosocial da militância nos anos 90, tudo isso teve função difusora (direta: livros, textos, músicas ou Indireta: linguagem, ideologia) de capital cultural, que muitas vezes teve mais qualidade (apesar de menor quantidade, em função do tempo) do que o oferecido no "sistema escolar", que negligencia saberes, especificando e afunilando os modos de pensar, segundo interesses diversos de elites dominantes. Bourdieu propõe a democratização dos ambientes de ensino, para que assim se possam conectar com conhecimentos diversos.

Relatos de pessoas semianalfabetas que possuem qualidades linguísticas tão abrangentes a ponto de, com completo entendimento dos termos técnicos, conversar sobre temas complexos com juristas como advogados e até juízes, serve para comprovar o fato de que não somente o formato padrão de educação fornecido pelas escolas serve para educar, mas também toda sorte de experiências, dentro de suas possibilidades. Tudo é aprendizado, desde que se possa contextualizar minimamente, o que parece ser impossível quando todos os métodos transmitidos the indicam um prisma especifico para olhar, esquecendo outros fatores que por vezes são imensamente importantes para compreensão dos temas.

Foi evidenciado também no texto que as pessoas se adaptam para aprender, se formatam para adquirir conhecimentos que julgam necessários. Houve a valorização da educação do sistema escolar padrão, mas não 
se perdeu de vista uma educação diferenciada, que tinha o intuito de transcorrer sobre temas considerados tão ou mais valiosos e abrangentes do que os do arbitrário cultural dominante. No entanto, percebe-se com Bourdieu, que para os interessados nesse tipo de trajetória acadêmica, é de suma importância a aquisição quantitativa e qualitativa desse tipo de conhecimento. Ele evidencia no texto os benefícios em se conhecer peças teatrais, músicas e livros, fatores culturais que facilitam a absorção da atmosfera de ensino diferente da de base, no caso acampamento em área pleiteada para assentamento de reforma agrária.

Diante de todo o exposto, pode se concluir que para alcançar o nível cultural que hoje possuo, fui apresentado a diferentes tipos e dosagens de capital cultural. Do teórico citado pelos militantes que frequentavam minha casa, aos livros que me emprestaram os mesmos, das músicas que meus pais me apresentaram, dos filmes que vimos juntos e do hábito sempre incentivado em casa, de leitura de livros diversos, até as discussões e análises político-sociais feitas durante a mesa de café da manhã, somaramse aos fatores apreendidos e traduzidos por mim, no sistema escolar. Posso afirmar seguro, que todos esses conhecimentos foram fundamentais para minha inserção na universidade, mas outros tantos conhecimentos (talvez mais indiretos) e que não cabem (por imposição do arbitrário cultural dominante) à educação acadêmica, tais como, o jogo de dominó, a luz do lampião no acampamento, as histórias de tradição oral transmitidas, os "causos da roça", as piadas, e todo um leque infinito de conhecimentos que foram fundamentais e, sem os quais não poderia abranger as análises e conclusões, expandi-las.

Evidencia-se também no texto o fator cultural, além de ressaltar a importância de alguns professores que agiram como difusores de um capital cultural diferente do modelo empregado no sistema escolar padrão, e não só isso, mas também o espírito de valorização do estudo e da educação (como aprendizado geral), e persistência na adaptação ao regime escolar, que infelizmente nem todos os profissionais da educação conseguem transmitir. Valores que são, hoje posso ver, elementos chave para minha entrada na universidade, e que fazem com que eu perceba a necessidade de mais difusores desse tipo de pensamento, o pensamento que resgata e democratiza os conhecimentos dispersos pelos diversos atores históricos ao longo do tempo. Para que todos os futuros licenciados em História percebam a importância de difusão e democratização do capital cultural.

\section{Referências}

BOURDIEU, P. A Escola Conservadora: As Desigualdades Frente à Escola e à Cultura. IN: NOGUEIRA, M. A. e CATANI, A. Escritos de Educação. Petrópolis: Ed.Vozes, 2003, p.41 - 64.

CASTRO, J. Geografia da fome (o dilema brasileiro:pão ou aço). 10a Ed. Rio de Janeiro: Ed. Antares; 1984, 348p.

FREIRE, P. Pedagogia do Oprimido. 42. ${ }^{\mathrm{a}}$ ed. Rio de Janeiro: Ed. Paz e Terra, 2005, $213 \mathrm{p}$.

THOMPSON, P. A voz do passado - História Oral. 2. ed. São Paulo: Ed. Paz e Terra, 1998.

WHITAKER, D.C.A.; FIAMENGUE, E.C.; VELÔSO, T.M.G. Ideologia e esquecimento: aspectos negados da memória social no Brasil. Presidente Venceslau: Ed. Letras A Margem, 2010, 268p. 